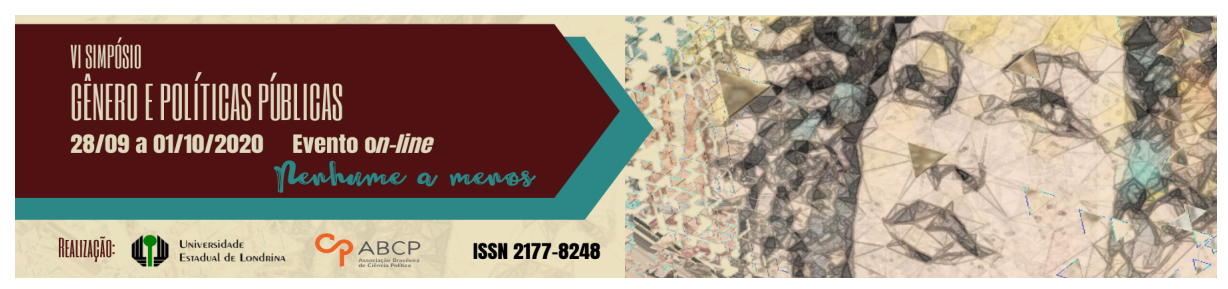

\title{
Centros de atenção psicossocial e expressões de gênero
}

\author{
Suelen de Oliveira Maas ${ }^{1}$; Luciana Elisabete Savaris ${ }^{2}$
}

\section{Resumo}

Centros de Atenção Psicossocial (CAPS) representam uma das formas de efetivar as propostas da Reforma Psiquiátrica Brasileira. O objetivo desse estudo será o de compreender se as expressões de gênero são consideradas relevantes no acolhimento e ofertas terapêuticas pelos profissionais que atuam em CAPS. A pesquisa contará com duas etapas, uma documental e uma de campo, contudo até o momento realizou se a revisão de literatura com vistas a estabelecer o estado da arte sobre as questões de gênero associadas ao cuidado em saúde mental. Resultou que é possível afirmar que as questões de gênero estão conectadas aos processos de subjetivação e sofrimento psíquico. Também a carga de estigma, preconceito e discriminação que permeiam a Saúde Mental estão presentes na discussão de gênero, gerando um processo de segregação que pode inibir aquele que sofre de buscar ou se manter em dispositivos de cuidado, o que reitera a relevância em investigar junto a profissionais que atuam em serviços especializados essa questão. Aspira-se com essa pesquisa suscitar o debate sobre gênero e saúde mental entre profissionais que atuam nos CAPS e estimular novas pesquisas a cerca desta temática.

Palavras-chave: expressões de gênero; centro de atenção psicossocial; saúde mental.

\section{Psychosocial care centers and gender expressions}

\footnotetext{
1Faculdades Pequeno Príncipe, formação, e-mail

2Faculdades Pequeno Príncipe, Psicóloga e Mestre em Saúde Coletiva, lucianaesavaris@gmail.com

GT 06 - Gênero, cuidado e políticas de saúde
} 


\begin{abstract}
Psychosocial Care Centers (CAPS) represent one of the ways to implement the proposals of the Brazilian Psychiatric Reform. The aim of this study will be to understand whether gender expressions are considered relevant in the reception and therapeutic offerings by professionals working in CAPS. The research will have two stages, one documentary and one in the field, however, so far, the literature review has been carried out with a view to establishing the state of the art on gender issues associated with mental health care. It turned out that it is possible to affirm that gender issues are connected to the processes of subjectification and psychological suffering. Also the burden of stigma, prejudice and discrimination that permeate Mental Health are present in the discussion of gender, generating a process of segregation that can inhibit those who suffer from seeking or maintaining themselves in care devices, which reiterates the relevance of investigating together to professionals working in specialized services on this issue. The aim of this research is to raise the debate on gender and mental health among professionals working in CAPS and to stimulate new research on this theme.
\end{abstract}

Keywords: gender expressions; psychosocial care center; mental health.

\title{
Introdução
}

Um novo modelo assistencial foi desenvolvido e CAPS foram implantados. Esses Centros representam uma das formas de efetivar as propostas da Reforma Psiquiátrica Brasileira (RPB), ampliando as fronteiras do cuidado em saúde mental para além dos muros manicomiais, passando a contar com serviços inseridos nas comunidades (ANDRADE, 2014; AMARANTE, 2018). Mas, para além do modelo assistencial, foi o debate acerca da garantia de direitos das pessoas com transtornos mentais que passou a ter evidência (YASSUI, 2010).

A carga de estigma, preconceito e discriminação permeiam a seara Saúde Mental. Zanello (2014) ressalta que questões de gênero também se mostram atravessadas historicamente pela segregação, fato que mobilizou a articulação dos temas, saúde mental e expressões de gênero. Observa-se que tanto "gênero" como "loucura", são conceitos 
produzidos culturalmente e que determinam o lugar que se ocupa na sociedade, refletindo no acesso e no tratamento ofertado as pessoas (QUADROS; SEVERIEN, 2009).

Este artigo se refere ao recorte do embasamento teórico que fundamenta a pesquisa em desenvolvimento nos Centros de Atenção Psicossocial do Município de Curitiba. O referencial teórico está pautado nas teorias de Beauvoir e Butler, e norteada pela seguinte questão de pesquisa: as expressões de gênero são consideradas relevantes no acolhimento e escolha de ofertas terapêuticas feitas por profissionais de saúde que atuam em CAPS? A escolha pelos CAPS se justifica por serem esses os dispositivos prioritários no cuidado em Saúde Mental, atendendo as demandas de um referido território adscrito e subsidiando intervenções dos outros pontos de atenção da Rede de Atenção Psicossocial.

\section{Método}

Trata se de um artigo de revisão, que analisou fontes de informações bibliográficas e eletrônicas para obtenção de resultados de pesquisas de outros autores, com o objetivo de fundamentar teoricamente o objeto. A partir dessas leituras foi possível promover o desenvolvimento do "estado da arte" sob ponto de vista teórico e contextual. Esse tipo de revisão se mostra adequada para a fundamentação teórica de pesquisas (LAKATOS, 2003).

\section{Reforma Psiquiátrica Brasileira}

O resgate da "história da loucura" no Brasil mostra que com a vinda da Família Real, em 1808, o cuidado em Saúde Mental começou a ser pensado no contexto nacional. As pessoas acometidas por alguma desordem psicológica eram internadas em Casas da Misericórdia, que possuíam caráter religioso, porém funcionavam "como cárceres", já que 
indivíduos ali internados "não possuíam qualquer tratamento humanizado" (FREITAS, 2018, p. 06). A pessoa dita louca é compreendida, nesse momento, como aquela que não se adequa aos padrões sociais e necessita ser excluída para não causar mal-estar ou envergonhar sua família (FREITAS, 2018). No processo de internamento, os sujeitos eram desprovidos de seu nome - possuíam um número de identificação - e de toda sua história de vida, tendo o mínimo para a sobrevivência e sendo tradado de forma desumana, sofrendo diferentes tipos de violações (ARBEX, 2013). Nesse processo, a maior "mudança" ocorreu no século XIX, no qual foi implementado o primeiro hospício, Hospício Dom Pedro II, no qual a prática deixa de ter cunho religioso e passa a ser psiquiátrica, isto é, voltada ao tratamento biológico das desordens mentais, porém ainda com tratamento desumanizado, por exemplo, o uso de eletrochoques indiscriminadamente e a utilização da lobotomia para "cura" da loucura (FREITAS, 2018).

Esse contexto desumanizado e carcerário se deu desde a era Colonial, no início do século XIX, até a Reforma Psiquiátrica Brasileira (RPB), no final do século XX. A Luta Antimanicomial, no Brasil, começa a ser pensada somente na década de 1970, ficando evidente com o I Encontro Nacional dos Trabalhadores em Saúde Mental, que ocorreu em 1987, com o lema: "Por uma sociedade sem manicômios". O evento teve como pauta a defesa da autonomia, o que estimulou: a restituição de direitos; a busca por eliminar coações e tutelas, e contenções nos tratamentos; e a promoção das relações e espaços de conversas. O Movimento Antimanicomial se intensifica durante os anos seguintes, mas somente em 2001, no Brasil de fato foi promulgada uma Lei e passou a implementar as mudanças efetivas no âmbito nacional (FREITAS, 2018).

A RPB lutou para extinguir a prática manicomial e garantir um tratamento digno a todas as pessoas, independentemente de qualquer característica ou extrato social. Propôs a extinção gradativa de leitos em 
Hospitais Psiquiátricos e a criação de uma Rede de Atenção Psicossocial, na qual questões de saúde mental passam a ser atendidas em diferentes equipamentos, tais como: Unidades Básicas de Saúde, CAPS, Unidades de Pronto Atendimento, Hospitais Gerais, entre outros. A RPB apoiou o cuidado territorial e integral (BRASIL, 2011; AMARANTE, 2015). Assim, foi promulgada a Lei n. 10.216/2001, que institui a proteção dos direitos das pessoas com transtornos mentais, garantindo o cuidado e tratamento digno dos sujeitos que necessitarem de atendimento (BRASIL, 2001).

Os CAPS nascem com a proposta de ofertar assistência a pessoas com Transtornos Mentais, próximo à comunidade, valorizando a singularidade e autonomia dos usuários. A expectativa é que os CAPS operem articulados aos demais serviços da Saúde e Intersetoriais, e "conhecer" os recursos comunitários do território onde está inserido. De modo que sejam agregadas todas as possibilidades e ofertas terapêuticas que possam favorecer a reinserção social de seus usuários (YASUI, 2010).

\section{Adoecimento psiquíco e gênero}

O saber médico imperou por muito tempo sobre os conhecimentos psicológicos. Nesse percurso, o adoecimento psíquico da mulher é associado com a não conformidade do papel social que possuía, por exemplo, o fato de não querer casar ou não querer ser mãe indicava a histeria, a desordem mental (COLLLING, 2015).

Os pensamentos médicos sobre a histeria fizeram Freud discorrer sobre conhecimentos psicológicos e estruturar sua Teoria Psicanalítica. Quanto à sexualidade, o autor formula que a mulher teria inveja do falo masculino e sua existência é marcada por essa inveja e a insatisfação com a falta fálica, vista como um homem incompleto (FREUD, 1976). De acordo com Colling a concepção freudiana sobre a "psicologia das mulheres não fica nada a dever aos padrões e valores 
culturais patriarcais e falocráticos" (2015, p. 196). A teoria teria dado "novo alento à antiga tradição do domínio masculino com a autoridade que lhe dava ser a mais nova das ciências" (COLLING, 2015, p. 196).

Segundo Viapiana, Gomes e Albuquerque (2018), esse pensamento voltado para a anatomia humana, a fim de explicar questões mentais, cria um aspecto biologizante do sofrimento. Nesse caso, suspende-se o indivíduo e suas vivências para focar nos sintomas e como tratá-los no corpo, ou seja, medicalizando os sintomas do corpo e não tratando as questões psicológicas (VIAPIANA; GOMES; ALBUQUERQUE, 2018). Como crítica a esse pensamento, os autores referem que o adoecimento ocorre no contexto social e cultural, de forma que o coletivo está relacionado, a partir das vivências nos grupos em que o indivíduo está inserido, e não pode ser desvinculado da estrutura social (VIAPIANA; GOMES; ALBUQUERQUE, 2018, p.178).

Corroborando com essa visão, Rosa e Lourenço afirmam que "historicamente o sofrimento mental esteve associado a 'Loucura', que, ao longo do tempo, teve um tratamento bastante discriminatório, para não dizer violento" (2012, p. 01). Procurou-se pelo tempo explicações diversas para a "loucura", como a influência cosmológica, místicas, religiosas até evoluir para as questões médicas e biológicas, mas sempre sem considerar os determinantes sociais no processo de saúde e doença, principalmente do adoecimento mental que é estigmatizado pela sociedade (ROSA; LOURENÇO, 2012).

Segundo Zanello o sofrimento psíquico não é composto somente pelo aspecto biológico, mas também por sua "expressão simbólica e construtiva", visto que "é mediado pela linguagem e pela cultura" (2014, p. 44). Segundo a autora, o sofrimento psíquico tem que ser compreendido em toda a sua extensão, "na qual os aspectos sociais e históricos específicos do sujeito confluem" (ZANELLO, 2014, p. 44). Santos corrobora com esse pensamento, para ele o sofrimento psíquico é construído socialmente e "traz em si a conformação dos valores e normas de uma determinada sociedade e época histórica" (2009, p. 2). 
Ou seja, não se pode olhar somente os sintomas que estão inscritos no corpo, mas é preciso observar o meio social e os grupos em que cada sujeito está inserido, a fim de proporcionar a integralidade do viver individual no tratamento.

Nascimento e Zanello (2014) agregam a essa discussão a questão de gênero e argumentam que essa questão está imbricada em processos de subjetivação e sofrimento psíquico. Estes autores questionam inclusive, se a experiência de enlouquecer do homem e da mulher é vivenciada da mesma forma, e buscam responder esse questionamento a partir de modelos sociais vigentes, ponderando que diferentes épocas históricas vão distinguir os papéis sociais e sua divisão ética.

A obra de Pessotti (1994), "Loucura das Épocas", inspira Nascimento e Zanello (2014) a refletir sobre esta questão, assim destacam os exemplos femininos da obra - mulheres acometidas pela loucura da paixão, loucas porque foram traídas, ou mesmo, possuídas de forma demoníaca (bruxas). Logo, se questionam: "será que os tipos de loucura que acometem os seres humanos retratados são os mesmos para homens e mulheres?" (NASCIMENTO; ZANELLO, 2014, p. 32).

Arbex (2013) fez uma reportagem sobre o tratamento dos doentes no manicômio de Barbacena em Minas Gerais, que resultou no livro "Holocausto Brasileiro", no qual cita uma série de acontecimentos desumanos e violentos dentro do manicômio. Como a autora ressaltou pacientes morriam de fome, frio e doenças por falta de saneamento básico, e até morriam de choque elétricos, que chegaram a derrubar a rede elétrica do município por conta da alta voltagem (ARBEX, 2013). Em seus relatos, aparecem diferentes questões sobre os internamentos, como a informação de que $70 \%$ das pessoas internadas não possuíam desordem mental. No prefácio do mesmo livro, Eliane Brum coloca que:

eram epiléticos, alcoolistas, homossexuais, prostitutas, gente que se rebelava, gente que se tornava incômoda para alguém com mais poder. Eram meninas grávidas, violentadas pelos seus 
patrões, eram esposas confinadas para que os maridos pudessem morar com a amante, eram filhas de fazendeiros as quais perderam a virgindade antes do casamento. Eram homens e mulheres que haviam extraviados seus documentos. Alguns eram apenas tímidos (2013, p. 14).

Entre os exemplos relatados tem-se a história de Conceição Machado, que foi internada pelo pai aos quinze anos, "porque decidiu reivindicar do pai a mesma remuneração paga aos filhos machos" (ARBEX, 2013, p. 39), pois desempenhava as mesmas funções que os irmãos. Ressalta-se que a maioria dos casos, constante no livro, são de mulheres que tiveram sua liberdade interrompida por "poderes maiores", majoritariamente, regidos por homens. Em suma, por essas mulheres não corresponderem a padrões sociais esperados, como as que engravidam de patrões, esposas que são "deixadas de lado", filhas que perderam a virgindade, entre outros, foram retiradas do convívio social. A autora relata casos de grávidas que perderam seus filhos assim que nasceram, pois foram levados à adoção, bem como relatos de abusos sexuais (ARBEX, 2013).

Também é interessante ressaltar que homossexuais eram internados, contra a vontade, por conta da orientação sexual, que por muito tempo foi tida como um desequilíbrio psíquico e, ainda hoje, é vista como uma perturbação da ordem social. A ponto de ser necessário, ao Conselho Regional de Psicologia, redigir a Resolução n. 01/99, que estabelece como profissionais da Psicologia devem atuar frente a questões de orientação sexual, que exibe o fundamental para a prática profissional: trabalhar com ética, sem preconceitos e sem patologização (BRASIL, 1999).

De acordo com Bento (2006) o pensamento dicotômico entre gêneros reproduz os sujeitos como universais, ou seja, existe o homem (masculino) e a mulher (feminino), esse binarismo determina características que supõe ser compartilhadas por todos os sujeitos. A discussão de como a loucura pode ser vista a depender do gênero, aqui 
ainda trabalhando com o conceito binário feminino-masculino, desencadeou o interesse em entender como se olha para essa questão. Hoje já se consideram múltiplas expressões de gênero, e essas expressões determinam a forma que o sujeito é visto e tratado na sociedade (BUTLER, 2018).

Adota-se nessa pesquisa os referenciais teóricos de Simone de Beauvoir (1949), que busca refutar a ideia de que biologicamente o macho é superior à fêmea humana por sua constituição física e química (BEAUVOIR, 2016). E, também, de Judith Butler (2018) que define expressão de gênero como a marcação de gênero feita pela cultura, que delimita as formas que indivíduos se expressa frente ao mundo, para embasar as reflexões.

Simone Beauvoir (1908-1986) foi uma filósofa existencialista, ativista política, feminista e teórica francesa que defendeu a igualdade aos gêneros; lutou contra a reprodução de costumes e fatores sociais, buscando deslocar o lugar da mulher na sociedade. Judith Butler (1956) é uma filósofa pós-estruturalistas, que estuda sobre as questões feministas, filosofias políticas e éticas; sua principal contribuição para os estudos de gênero foi a construção da Teoria Queer.

Nesse sentido, a forma de expressão de gênero aceita pela sociedade é delimitada por uma heterossexualidade compulsória, ou seja, masculino e feminino são aceitos como as únicas formas de expressão possíveis, no qual o macho da espécie - aquele que porta o pênis - deve se portar como o masculino na representação social, assim como, a fêmea da espécie - aquela que possui uma vagina - deve se portar como a representação feminina (BUTLER, 2018, p.44). Corroborando com esse pensamento, Bento coloca que "a identidade de gênero, as sexualidades, as subjetividades só apresentam uma correspondência com o corpo quando é a heteronormatividade que orienta o olhar" (2006, p. 23), ou seja, é quando pensado pelo viés da heterossexual que o homem deve se portar como homem e a mulher como mulher, de acordo com as conformações sociais vigentes. 
Beauvoir (2016) empresta a perspectiva psicanalítica de Freud que sustenta a superioridade do homem por possuir o "falo" e a inveja da mulher em relação ao homem e contra argumenta. De acordo com a autora, a criança ainda não tem consciência de sua condição enquanto homem ou mulher, mas sentem curiosidade frente aos órgãos genitais. A "inveja" da menina sobre o menino é derivada do tratamento que ele recebe por possuir um pênis, sendo evidente a diferença no tratamento, por exemplo, quando ao menino é permitido brincar e descobrir o mundo e a menina deve ser devotada ao lar, aprendendo a realizar os afazeres domésticos e a como cuidar das crianças e dos homens (irmãos, pai e o futuro marido) (BEAUVOIR, 2016).

Retomando Butler, existem gêneros aceitos socialmente ou ditos por ela "inteligíveis" - são aquele que "instituem e mantêm relações de coerência e continuidade entre sexo, gênero, prática sexual e desejo" (2018, p. 43). Contudo, isso é uma falácia, pois cada sujeito é único em sua forma de se relacionar e não é possível uma generalização esperando que o sexo biológico se correlacione com os desejos e gênero expresso. Preciado (2014), em seu livro "Manifesto Contrassexual", crítica a heteronormatividade e, assim como Butler, ressalta a interferência da cultura na construção de gênero.

De acordo com Bento (2006) a questão do corpo, como natural frente ao gênero como constructo social não faria sentido, pois ambos não são anteriores a cultura, as concepções sociais sobre o corpo ou gênero só existem a partir de tecnologias culturais.

Butler (2018) é a autora da Teoria Queer, na qual propõe que as expressões - ou performances - de gênero vão além do masculino e feminino. Nesse sentido, é construído socialmente o que se espera de uma mulher lésbica ou de um homem gay e não entrar nessa conformidade gera o sofrimento de diferentes preconceitos. É por isso a autora se refere à expressão de gênero como queer, ou seja, cada pessoa possui sua singularidade em expressar seu gênero, sem precisar performar o que é estabelecido socialmente, que seria a conformidade 
entre sexo-gênero-sexualidade (BUTLER, 2018, p. 25). Bento (2006) explica que a palavra queer foi utilizada por muito tempo como um termo pejorativo, que significa "estranho/a", designando pessoas que não estavam em conformidade com o gênero estabelecido pela heterossexualidade. Porém, dentro desse processo, indivíduos LGBT+ passaram a utilizar esse termo como uma forma de resistência que, então, passa a significar "colocar-se contra a normalização".

Ao congregar as questões de gênero e cuidado em saúde mental, Zanello e Silva (2012) discutem que profissionais também são influenciados/as pela cultura na qual estão inseridos e que essa influência interfere no modo como veem os pacientes. Segundo eles, "os olhares" também são marcados pelos valores de gênero, os quais se tornam fatores determinantes "na atividade hermenêutica da leitura dos sintomas" (ZANELLO; SILVA, 2012, p. 269).

Nesse contexto, é possível emprestar os pensamentos da Serge Moscovici (2011) quanto à Teoria das Minorias Ativas, onde todos os indivíduos que participam da sociedade são receptores e emissores de mensagens, ou seja, podem influenciar uns aos outros conforme se relacionam. Porém, o corpo majoritário tem maior poder sobre a influência das informações e práticas sociais, com isso, pode-se pensar que, sendo o pensamento heteronormativo que tem maior poder, ele influencia a todos os indivíduos que produzem a sociedade, isso inclui os/as profissionais. Contudo, pode-se pensar que, como traz Moscovici (2011), as minorias sendo ativas e organizadas, possuem um poder de fala validado ao longo do tempo, os preceitos dessa minoria podem influenciar o modo de pensar dos profissionais.

Assim como as representações sociais que, definidas como características que estabelecem um conhecimento prévio sobre determinado objeto, conceito e/ou pessoa e que é criado a partir da interação social, podem auxiliar a compreender como conceitos sociais influenciam o pensamento de profissionais (MOSCOVICI, 2019). Porém, o autor argumenta que "pessoas e grupos, longe de serem 
receptores passivos, pensam por si mesmo, produzem e comunicam incessantemente suas próprias e específicas representações e soluções as questões que eles mesmos colocam" (MOSCOVICI, 2019, p. 45). O que pode influenciar outros grupos sobre seus posicionamentos e/ou produzir mudanças dentro do contexto social em que se inserem.

Ao pesquisar sobre a diferença entre a ocorrência de transtornos mentais em homens e mulheres, foram encontradas pesquisas como as de Andrade, Viana e Silveira (2006); Rabasquinho e Pereira (2007); Santos (2009), e Zanello (2014) demostram que existe uma prevalência de transtornos de humor em mulheres. Quanto ao uso abusivo de substâncias psicoativas, transtornos de personalidade, transtorno do controle de impulsos e déficit de atenção, estes mostram se mais comuns em homens. Santos (2009) associa o sofrimento psíquico feminino a questões de violência doméstica e repressão sexual. Já o sofrimento masculino está ligado a rupturas da trajetória de vida, uma exclusão de espaços.

Campos, Ramalhos e Zanello (2017), desenvolveram uma pesquisa com os prontuários de usuários de CAPS, quanto às questões de gênero, elencando as diferenças e similaridades nesse processo de adoecimento psíquico. De acordo com os autores, foi possível perceber que, na fala das mulheres estavam relacionados processos de criação dos filhos, trabalhos domésticos, sentir solidão em relação ao marido, relação conflituosa com a mãe (e pouco relacionaram conflitos ao pai), processos de sofrimento por conta do matrimônio (traição, violência). Porém, esses aspectos não foram vistos nos processos de adoecimento dos homens (CAMPOS; RAMALHOS; ZANELLO, 2017, p. 74).

A questão laboral foi vista em ambos os casos, entretanto os autores ressaltam que "o termo 'sobrecargas' apareceu associado ao trabalho das mulheres no âmbito privado, como doméstica e ou cuidadora de pessoas doentes na família" (CAMPOS; RAMALHOS; ZANELLO, 2017, p. 4). 
O adoecimento psíquico, segundo Zanello (2014), pode ser entendido por duas perspectivas, uma "biologizante", que busca a causa no organismo e funções biológicas, e outra "sócio-histórica", que ressalta as questões sociais envolvidas no processo. Nascimento e Zanello (2014) sinalizam que historicamente o adoecimento psíquico foi sendo explicado de modo diferenciado para homens e mulheres, no caso dos homens uma leitura "biologizante" e para as mulheres, causas morais.

Além da prevalência de determinados diagnósticos, Santos também considera que o gênero estabelece formas diferentes de vivenciar o adoecimento psíquico: "essas diferenças podem ser observadas desde o surgimento da primeira crise psicótica até a relação que esses usuários estabelecem com o CAPS" (2009, p. 4). Enquanto que Rodrigues (2015) problematiza a importância de se considerar no atendimento à saúde mental, diferenças relacionadas a gênero. Porém, conforme sinalizam Nascimento e Zanello (2014), essa questão permanece sendo silenciada. Empreendendo buscas por estudos que discutissem o atendimento em Saúde Mental relacionados às diferentes expressões de gênero, foram encontradas prioritariamente pesquisas voltadas ao binarismo homem-mulher.

Quando pesquisadas as demais expressões de gênero, como gays e lésbicas, os estudos do adoecimento psíquico estão voltados para a discriminação e o preconceito sofrido que geram interferência no psiquismo. Como exemplo, os artigos: "Saúde e população LGBT: demandas e especificidades em questão" de Cardoso e Ferro (2012), e "Foi como se a gente tivesse visto a morte: estigmatização, sofrimento psíquico e homossexualidade", de Rios e colaboradores (2018), que versam sobre a temática dos preconceitos sofridos que geram depressão, ansiedade e outros conflitos internos.

\section{Considerações finais}


A carga de estigma, preconceito e discriminação que permeiam a Saúde Mental estão presentes na discussão de gênero, podem gerar um processo de segregação e podem inibir os in divíduos que sofrem de buscar ou se manter em dispositivos de cuidado como são os CAPS.

É possível afirmar que as questões de gênero estão conectadas aos processos de subjetivação e sofrimento psíquico, portanto as expressões de gênero devem ser consideradas relevantes no acolhimento e ofertas terapêuticas pelos profissionais que atuam em serviços especializados em saúde mental como os CAPS.

Infere-se que é pertinente prosseguir no intuito de pesquisar tanto os conteúdos presentes nos textos dos Projetos Institucionais dos CAPS como a pesquisa de campo junto a profissionais que ali atuam. Espera se com esse estudo contribuir dando visibilidade ao tema.

\section{Referências}

AMARANTE, P. Saúde mental e atenção psicossocial. 4. ed. Rio de Janeiro: Fiocruz, 2015.

AMARANTE, P.; NUNES, M. O. A reforma psiquiátrica no SUS e a luta por uma sociedade sem manicômios. Ciênc. saúde coletiva, Rio de Janeiro, v. 23, n. 6, p. 2067-2074, jun. 2018.

ANDRADE, A. P. M. (Entre)Lançamentos possíveis entre gênero e saúde mental. In: ZANELLO,V.; ANDRADE, A. P. M. de (Org.). Saúde mental e gênero: diálogo, práticas e interdisciplinaridade. Curitiba: Appris, 2014. 244p. p. 59-77.

ANDRADE, L.H.S.G.; VIANA, M.C.; SILVEIRA, C.M. Epidemiologia dos transtornos psiquiátricos na mulher. Rev. Psiq. Clín. n. 33, p. 43-54, 2006.

ARBEX, D. Holocausto brasileiro. São Paulo: Geração Editorial, 2013.

BEAUVOIR, S. O segundo sexo: fatos e mitos. V. 01. 3. ed. Rio de Janeiro: Nova Fronteira, 2016a. 
BEAUVOIR, S. O segundo sexo: a experiência vivida. V. 02. 3. ed. Rio de Janeiro: Nova Fronteira, 2016b.

BRASIL. Conselho Federal de Psicologia. Resolução n. 01 de 1999. Disponível em: https://site.cfp.org.br/wpcontent/uploads/1999/03/resolucao1999_1.pdf. Acesso em: 10 ago. 2020 .

BRASIL. Presidência da República. Casa Civil. Subchefia para Assuntos Jurídicos. Lei n. 10.216, de 6 de abril de 2001. D. O. U. de 09. 04. 2001. Disponível

em:

http:// www.planalto.gov.br/ccivil_03/LEIS/LEIS_2001/L10216.ht m. Acesso em: 04 ago. 2020.

BRASIL. Ministério da Saúde. Gabinete do Ministro. Portaria n. 3.088, de 23 de dezembro de 2011. D. O. U. n. 247, de 26-12-2011, seção 1, p. 230-232. Disponível em: http:// bvsms.saude.gov.br/bvs/saudelegis/gm/2011/prt3088_23_ 12_2011_rep.html. Acesso em: 04 ago. 2020.

BENTO, B. A reinvenção do corpo: sexualidade e gênero na experiência transexual. Rio de Janeiro: Garamond, 2006.

BUTLER, J. Problemas de gênero: feminismo e subversão da identidade. 16. ed. Rio de Janeiro: Civilização Brasileira, 2018.

CAMPOS, I. O.; RAMALHOS, W. M.; ZANELLO, V. Saúde mental e gênero: o perfil sociodemográfico de pacientes em um centro de atenção psicossocial. Estud. Psicol, Natal, v. 22, n. 1, 2017.

COLLING, A. M. A construção histórica do corpo feminino. Caderno Espaço Feminino, Uberlândia, v. 28, n. 2, p. 180-200, jul./ dez. 2015.

FREITAS, B.L. A Evolução da Saúde Mental no Brasil: reinserção social. Revista Científica Semana Acadêmica, Fortaleza, a. MMXVIII, v. 1, n. 126, jul. 2018.

FREUD, S. Feminilidade. V. XXII. Rio de Janeiro: ESB; Imago, 1976.

MOSCOVICI, S. Psicologia das minorias ativas. Petrópolis: Vozes, 2011.

MOSCOVICI, S. Representações sociais: investigação em psicologia social. 11. ed. Petrópolis: Vozes, 2019. 
NASCIMENTO, W. F.; ZANELLO, V. Uma história do silêncio sobre gênero e loucura - Parte I. Sobre o que não se fala em uma arqueologia do silêncio: as mulheres em História da Loucura. In: ZANELLO,V.; ANDRADE, A. P. M. de. (Org.). Saúde mental e gênero: diálogo, práticas e interdisciplinaridade. Curitiba: Appris, 2014. 244p. p. 17-28.

PESSOTTI, I. Loucura das épocas. Campinas: Editora 34, 1994.

PRECIADO, B. Manifesto contrassexual. São Paulo: n-1 edições, 2014.

QUADROS, M. T.; SEVERIEN, E. O que é gênero? In: SEVERIEN, E.; QUADROS, M. T. Mulheres nos caminhos do empoderamento: escola feminista nos bairros/comunidades. Recife: Espaço Feminista, 2009.

RABASQUINHO, C.; PEREIRA, H. Gênero e saúde mental: uma abordagem epidemiológica. An. Psicológica, Lisboa, v. 25, n. 3, 2007.

RIOS, L. F. et al. Foi como se a gente tivesse visto a morte: estigmatização, sofrimento psíquico e homossexualidade. Laplage Em Revista, v. 4, n. 1, p. 140-158, 2018.

RODRIGUES, T. F. desigualdade de gênero e saúde: avaliação de políticas de atenção à saúde da mulher. Rev. Cantareira, n. 22 p. 203216, jan./jul. 2015.

ROSA, C. R.; LOURENCO, E. A. S. Os determinantes sociais e o adoecimento mental. In: Anais- VIII Seminário do Trabalho: trabalho, educação e politicas sociais no século XXI. Marília: RET, 2012. p. 1-8.

SANTOS, A. M. C. C. Articular saúde mental e relações de gênero: dar voz aos sujeitos silenciados. Ciênc. saúde coletiva, v. 14, n. 4, p. 11771182, 2009.

VIAPIANA, V. N.; GOMES, R. M.; ALBUQUERQUE, G. S. C. Adoecimento psíquico na sociedade contemporânea: notas conceituais da teoria da determinação social do processo saúdedoença. Saúde debate, v. 42, n. spe 4, p.175-186, 2018.

YASSUI, S. Rupturas e encontros: desafios da reforma psiquiátrica brasileira. Rio de Janeiro: Fiocruz, 2010. 
ZANELLO, V. A. Saúde mental sob o viés do gênero: uma releitura gendrada da epidemiologia, da semiologia e da interpretação diagnóstica. In: ZANELLO,V.; ANDRADE, A. P. M. de. (Org.). Saúde mental e gênero: diálogo, práticas e interdisciplinaridade. Curitiba: Appris, 2014. 244p. p. 41-58.

ZANELLO, V.; SILVA; R. M. C. Saúde mental, gênero e violência estrutural. Revista de Bioética, v. 20, n. 2, p. 267-279, 2012. 